\title{
The energy charts for occupants' behavioural improvement through BIM
}

\author{
Rasyikin Roslan ${ }^{1}$, Rohayu Che Omar ${ }^{2 *}$, Hairin Taha ${ }^{1}$, Intan Nor Zuliana Baharuddin ${ }^{1}$, and Ratih Fitria Putri ${ }^{3}$ \\ ${ }^{1}$ Institute of Energy Infrastructure, Universiti Tenaga Nasional, 43000 Kajang, Malaysia \\ ${ }^{2}$ Department of Mechanical Engineering, Universiti Tenaga Nasional, 43000 Kajang, Malaysia \\ ${ }^{3}$ Department of Environmental Geography, Faculty of Geography, Universitas Gadjah Mada, Yogyakarta, 55281, Indonesia
}

\begin{abstract}
BIM is an easy method to design sustainable buildings for professionals like architects and engineers. By using the real measurable environment, software tools can shape building concepts such as geometry, spatial relations, geographical details and the design of structural composites and buildings, and the usage of energy annual like energy costs and life-cycle costs can be estimated and calculated. This study revealed the findings of the energy consumption within one year can provide valuable insights into the projected resources in the UNITEN Administrative Building. The application of these data would simplify energy cost calculation, an essential component of the costs of operating a property. With the purpose of maximizing energy efficiency in green buildings, the outcomes can be used as guidance to advice occupant management in optimizing occupant actions.
\end{abstract}

\section{Introduction}

Crucial decisions on the construction of sustainable buildings are initially achieved conceptually during the development process. In general, energy modelling analysis is performed when the design and documents relating to the buildings have been created [1].

The American Architects Institute (AIA) has acknowledged the application of Building Energy Modelling (BEM) in projects involving energy-efficient building for its stakeholders. BEM enables designers plan and develop energy-efficient and high-performance buildings. Performance-based modelling provides housing owners with lower project lifecycle costs such as change orders, lower initial costs, maintenance and operating costs and at the same time, building occupants can achieve comfort and healthy indoor environment [2].

Systems adopting Green building certification can be applied as standard guidance for building comparisons, record progress and documentation of information and strategies used in buildings [3]. There are various systems of green building certifications and methodologies that are applicable for classification purposes such as the Building Research Establishment Environmental Assessment Method (BREEAM), the Building and Environmental Performance Assessment Criteria (BEPAC, Canada), the Leadership in Energy and Environmental Design (LEED,US), and the Green Star (GBCA, Australia) [3] which are widely used to determine the level achievement of environmental targets and to guide the process of planning. Besides, comprehensive environmental assessment guides such as the World Green Building Council and the Building
Design Guide were also used to evaluate the building performance for green index building [1] and [3].

The experimental method is proposed in the design using different efficiency criteria specific to the construction of buildings such as building materials for roofs and walls and the ratios of window-to-wall [4], [5], [6]. The results suggest that data on climate plays an important role in selecting construction considerations that are ideally suited for the productive use of energy in buildings. Specifically, in contrast to the main climate group, sub-type climate classifications have a limited effect [4], [6] and [7].

As example for window-to-wall ratio, the architectural factor improvement results in an increment of $15 \%$ energy use in buildings. The insights gleaned from this study include the impact of space, material thickness and exterior openings, and the types of building envelopes in all climate classifications, which are included to design low-energy buildings [4], [5], [7] and [8].

Building efficiency analyses are essential aspects of sustainable building design. Performance analysis generally helps to determine how buildings work as a result of daylighting in terms of their built material and the light environment. The built material use shows a progressive reduction of environmental effects during the building's lifecycle, such as energy usage. Building information modelling (BIM) has described as an essential method for building performance analyses from the design to the maintenance process [9], [10] and [11].

The Revit Architecture 2017 and Low Carbon Cities Framework (LCCF) and the KeTHHA 2015 assessment system are used to determine the best energy

\footnotetext{
* Corresponding author: rohayu@uniten.edu.my
} 
performance and low carbon city assessment using alternative material configurations [12].The Revit modelling highlights the different building materials and design principles by defining alternatives using innovative approaches to significantly minimize the building's operating energy usage during its annual life cycle and quality requirements for cities with low carbon dioxide. By the conclusion of the research study, an energy usage and energy performance chart help to educate staff and strategies for enhancing energy efficiency that impact occupants' behavioural improvement is crucial.

\section{Methodology}

\subsection{Experimental site}

UNITEN Administration Building $\left(2^{\circ} 58^{\prime} 39.2^{\prime \prime} \mathrm{N}\right.$, $\left.101^{\circ} 43^{\prime} 53.1^{\prime \prime E}\right)$ use as a sample of case study to evaluate the performance of the building with respect to energy analysis as shown in Figure 1 and Figure 2. Autodesk Revit and Green Building studio were used to simulate the UNITEN administration building to generate the energy model for energy performance and green building index. The location and analysis of the site are the main elements that can affect the position of the buildings. These contributing factors could be used to determine the spatial orientation and facade of the buildings and to develop the construction of the surrounding landscape.

The main research tool used by architects and engineers in the visualization of 3D models is the Building Information Modelling (BIM) system. The physical and technical features of a visual building through BIM energy analysis use to calculate the energy efficiency and thermal comfort of a building [13] and [14]. The data processed include the geometry and orientation of the building and their thermal properties, the types and categories of materials used, the lighting, cooling, heating, and ventilation systems including the recent utility rates and weather data and observations.

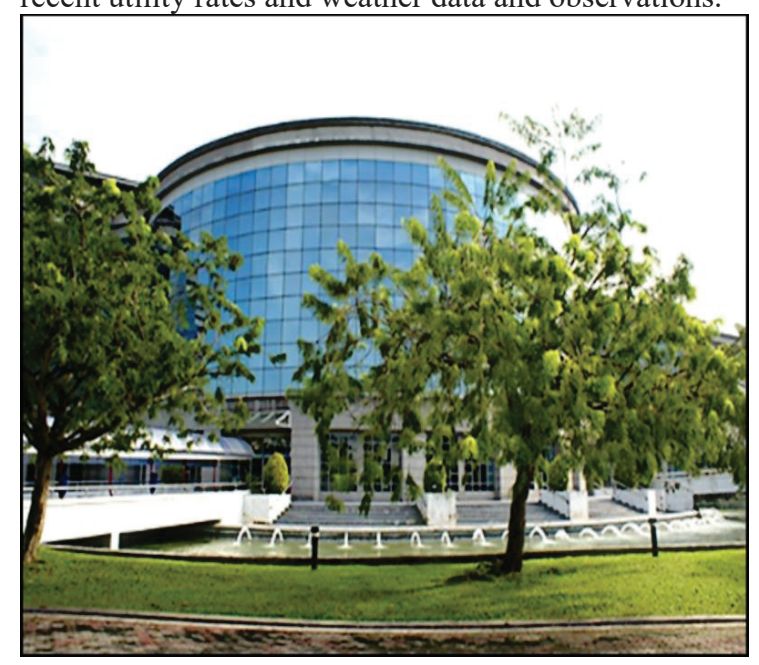

Fig.1. UNITEN administration building.

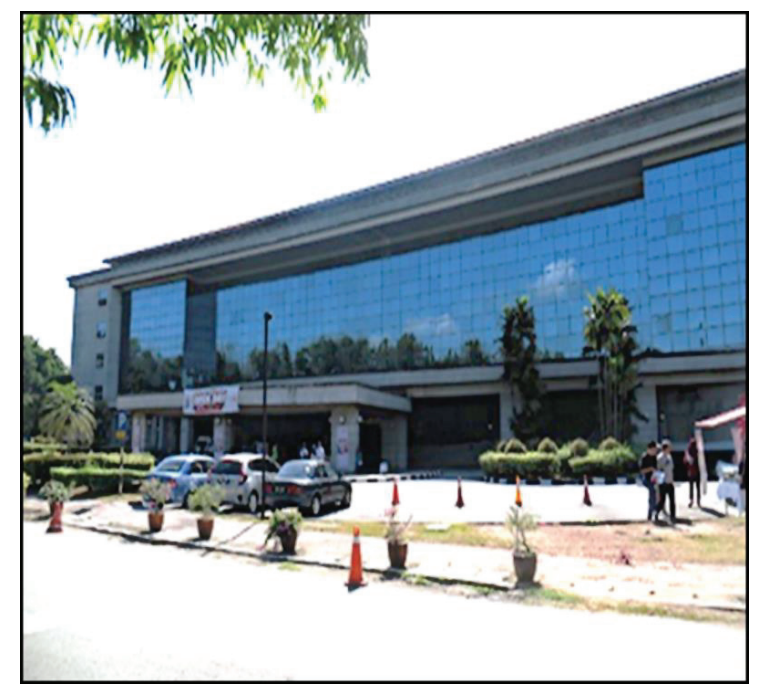

Fig.2. Front part of UNITEN administration building.

\section{Result and discussion}

\subsection{Autodesk Revit Software and GBS analysis}

Primary and secondary data, including the as-built administrative UNITEN building drawings to be analysed, were collected. The primary data collected using laser scanning mapping and the secondary data from hardcopy transformed to digitalization to suit the standard used in building information modelling (BIM). The drawing is registered in Autodesk Revit software and transforms into a 3D model as shown in Figure 3, featuring building components like windows, walls and floors that are created for energy simulation to suit various designs and building elements.

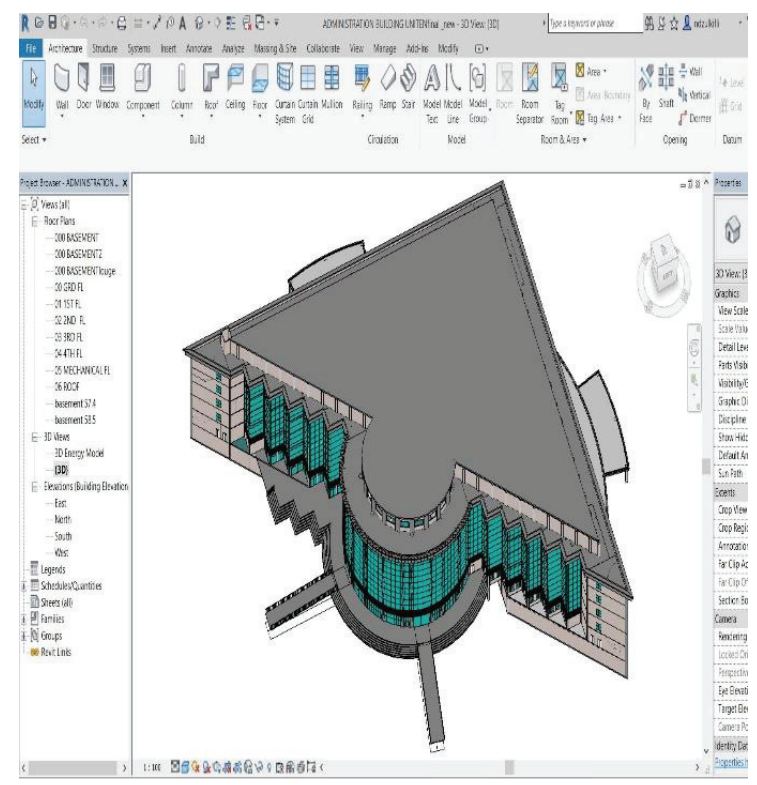

Fig.3. A 3D model. 


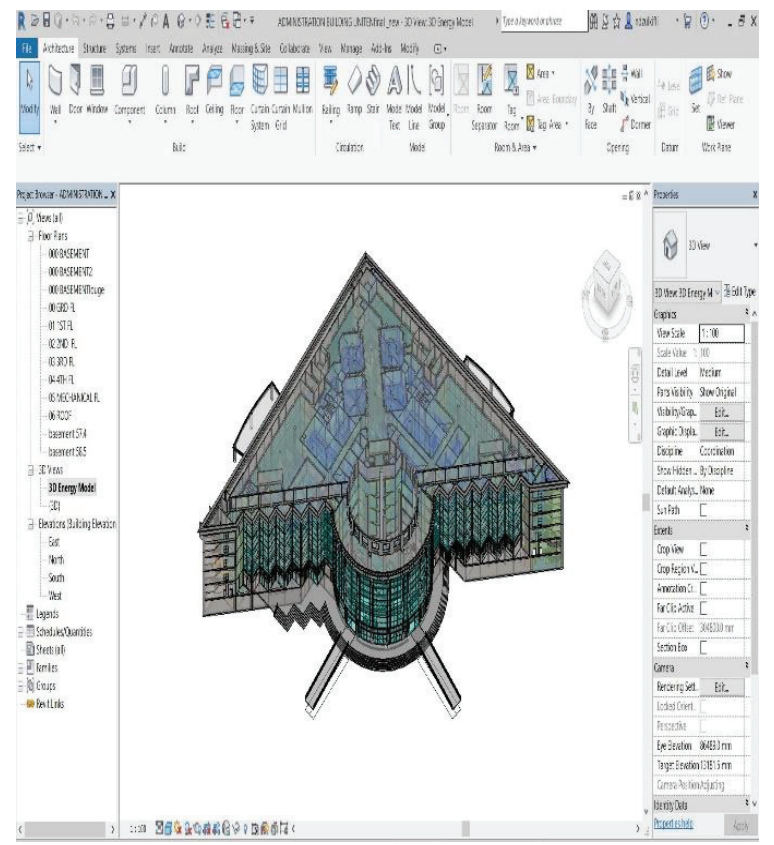

Fig. 4. Energy model in 3D.

\subsection{Green Building Studio software analysis}

The energy modelling and analysis of the building were processed using the Green Building Studio (GBS) which is a cloud-based simulation tool as illustrated in Figure 3 and Figure 4. The extensible green construct Language gbXML file format was used to connect BIM software to external simulation tools.

The results provided a simulation of building performance that allows users to improve energy consumption and efficiency by reducing carbon emissions to ensure sustainable buildings. The GBS results show that in this building occupied up to 1,208 people, with the use of average lighting power density $10.67 \mathrm{~W} / \mathrm{m} 2$ lower than typical value, average equipment power density up to $10.61 \mathrm{~W} / \mathrm{m} 2$, specific fan flow 3.9 LPerSec/m2, total fan flow 22,214 LperSec, specific cooling and specific heating lower than typical value, i.e. $0 \mathrm{~m} 2 / \mathrm{kW}$ and total cooling and heating capacity less and not more than $12,484701 \mathrm{~kW}$, as shown in Figure 5.

The summary of the results were then analysed for the amount of electrical energy consumption, water usage and annual energy costs and fuel emissions report for carbon dioxide (CO2) as demonstrated in Figure 5, Figure 6, Figure 7 and Figure 8. The annual energy cost indicates as RM1, 598,722.00, with a life cycle cost RM566, 574,590.00. Once the energy analysis and conceptual design are completed, the building is then evaluated and analysed using the life cycle assessment (LCA) module based on sustainability requirements. The calculation of the main operating energy including embodied energy such as the refine and deliver energy, extracted energy and emissions of air, water and land over the life cycle of the UNITEN administration building was carried out by using the Impact Estimator (IE) in this software as shown in Figure 5 and Figure 6. Apart of that, other environmental effects of the
UNITEN administration building also displayed the inherent trade-offs which are associated to the increase in insulation that decrease operational energy consumption (Figure 6 and Figure 8).

The energy chart and analysis in Figure 8 showed the significant factors that affect the energy consumption of the analyzed model in the Administrative UNITEN building. The results showed that most annual electric use derived from lighting systems $(19.1 \%)$, air condition system $(58.70 \%)$ and others $(22.3 \%)$. It showed that usage of energy that contribute to the annual electric end-use was projected by the behavior of electric consumers in the building. The cause was due to the lack of preparation of building occupants in the utilization of electrical equipments, unpredictable actions of occupants, preference of comfort criterion for occupants, lack of the goal of energy consumption by the occupants, the behavioural difference between occupants, lack of understanding and the lack of coordination on the particular required behaviors.

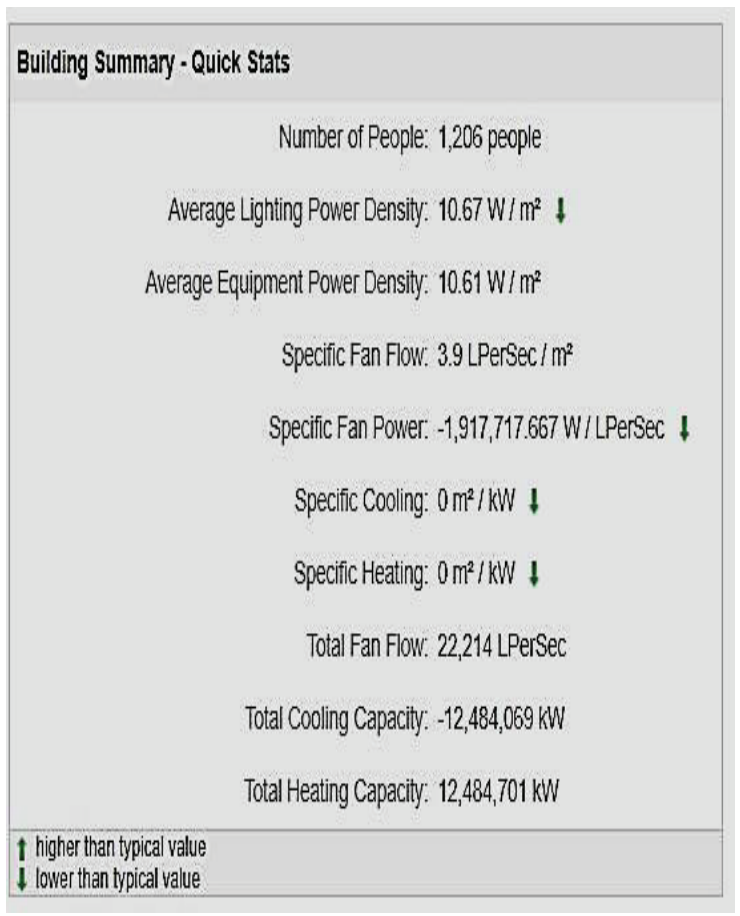

Fig. 5. The GBS building summary. 


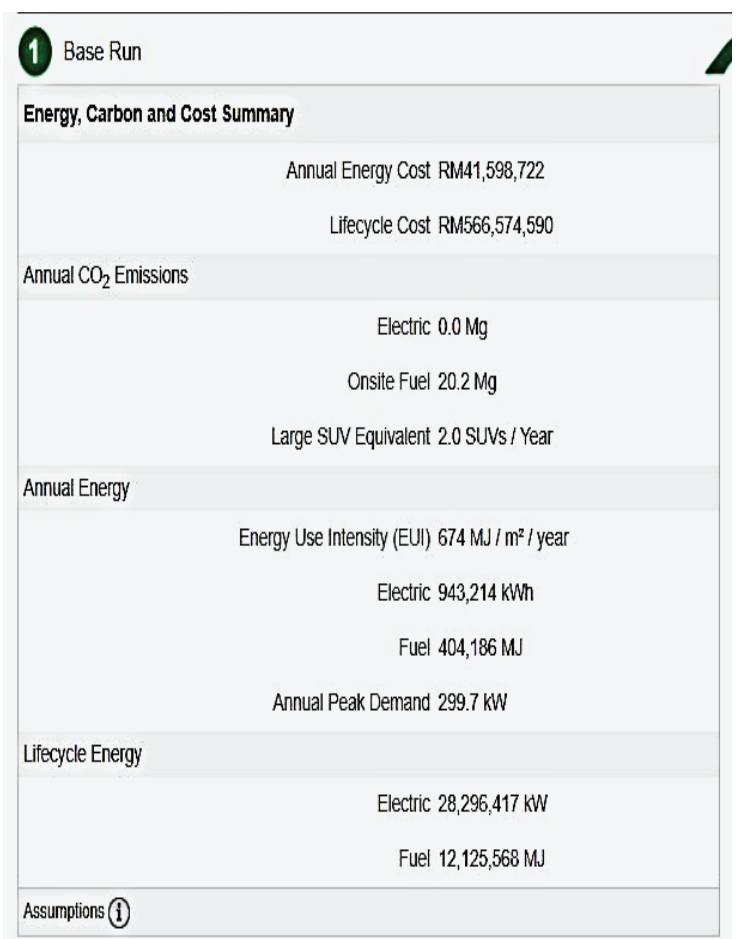

Fig. 6. The energy, carbon and cost summary.

\begin{tabular}{|c|c|c|}
\hline Carbon Footprii & & \\
\hline \multicolumn{3}{|c|}{ Base Run Carbon Neutral Potential (3) } \\
\hline \multicolumn{3}{|c|}{ Annual $\mathrm{CO}_{2}$ Emissions } \\
\hline & (1) Base Run & N/A \\
\hline & Onsite Renewable Potential & N/A \\
\hline & Natural Ventilation Potential & N/A \\
\hline & Onsite Biofuel Use & N/A \\
\hline & Net $\mathrm{CO}_{2}$ Emissions & N/A \\
\hline \multicolumn{3}{|c|}{ Net Large SUV Equivalent: N/A } \\
\hline \multicolumn{3}{|l|}{ Assumptions (1) } \\
\hline \multicolumn{3}{|c|}{ Electric Power Plant Sources in Your Region } \\
\hline & Fossil & N/A \\
\hline & Nuclear & N/A \\
\hline & Hydroelectric & N/A \\
\hline & Renewable & N/A \\
\hline & Other & N/A \\
\hline Assumptions (1) & & \\
\hline
\end{tabular}

Fig. 7. The carbon footprint analysis.

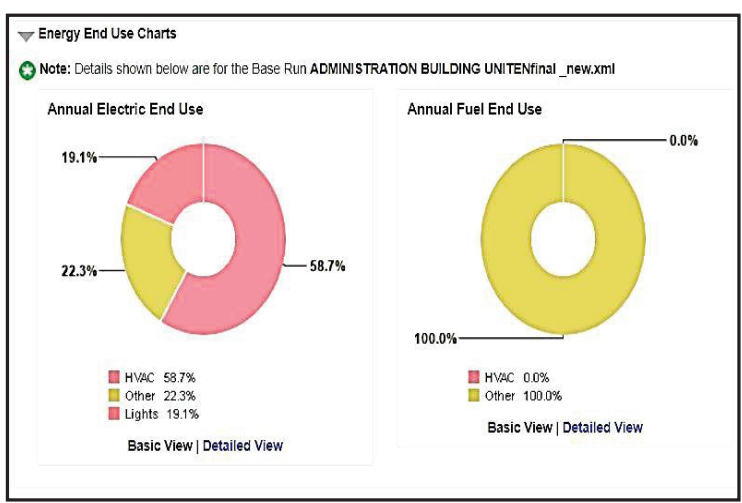

Fig. 8. The energy chart.

\section{Conclusion}

The findings of the energy analysis offer a valuable perspective on the expected energy to be obtained or lost in the UNITEN administrative building within one year. The application of these data would simplify the estimation of energy cost, which contributed largely to the running costs of any building. Life Cycle Cost consolidates environmental and energy impacts, which had a significant effect on the future building portion, as against traditional building estimates. In addition to obvious environmental advantages, Green Building Certification is less costly to maintain and better suited for industrial and residential occupants. Therefore, the results used to educate the occupant's behaviour and strategy that effect occupant behavioural change is vital in order to enhance the energy performance towards green building initiative.

This study was funded by UNITEN internal grant (J 510050715). The authors thank Mr Aiman for his assistance in data processing and compilation. Thanks, Universiti Gadjah Mada, Indonesia for geographical, behavioural analysis study and partnering as co-authorship.

\section{References}

1. F. Jalaei, A. Jrade, ITCon 19,211-220 (2014)

2. The American Institute of Architects (AIA), Integrating energy modelling in the design process, (The American Institute of Architects: Washington, DC, USA, 2012)

3. N. Wang, K. M. Fowler, R.S. Sullivan, Green building certification system review, (Pacific Northwest National Laboratory, Battelle for USDOE and US GSA; Whole Building Design Guide (WBDG), 2012)

4. J. Hong, G. Shen, Y. Feng, W. S. T. Lau, C. Mao, Cleaner Production 103, 249-259 (2015)

5. A. Allouhi, Y. El Fouih, T. Kousksou, A. Jamil, Y. Zeraoulli, Y. Mourad, Cleaner Production 109, 118-130 (2015)

6. M. K. Najjar, V. W. Y. Tam, L. T. D. Gregorio, A. C. J. Evangelista, A.W.A. Hammad, A. Haddad, Energies 12, 1515 (2019) 
7. F. H. Abanda, L. Byers, Energy 97, 249-259 (2016)

8. A. Alwisy, S. BuHamdan, M. Gul, Energy and Buildings 178, 347-259 (2018)

9. H. Khan, M. Asif, Sustainabilty 9, 4:640 (2017)

10. M. V. Shoubi, M. V. Shoubi, A. Bagchi, A. S. Barough, Ain Shams Engineering Journal 6, 1:41-55 (2015)

11. J. B. Kim, W. Jeong, M. J. Clayton, J. S. Haberl, W. Yan, Automation in Construction 50, 16-28 (2015)

12. F. Jalaei, A. Jrade, Sustainable Cities and Society 18, 95-107

13. C. C. Ohueri, W. I. Enegbuma, K. K. Kuok, N. M. Wong, L. T. Ng, R. Kenley, Preliminary evaluation of synergizing BIM and Malaysian carbon reduction and environmental sustainability tool, in International Conference on Sustainability in Energy and Buildings, June, Springer, Cham (2018)

14. H. J. Kuo, S. H. Hsieh, R. C. Guo, C. C. Chan, Energy and Buildings 130, 95-107 (2016) 